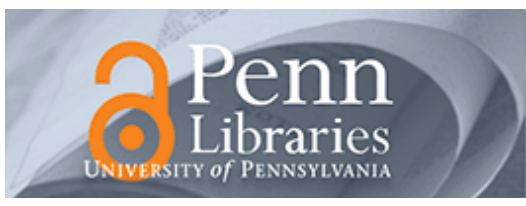

University of Pennsylvania ScholarlyCommons

4-1995

\title{
Are Foreign Exchange Intervention and Monetary Policy Related and Does It Really Matter?
}

Karen K. Lewis

University of Pennsylvania

Follow this and additional works at: http://repository.upenn.edu/fnce_papers

Part of the Finance Commons, and the Finance and Financial Management Commons

\section{Recommended Citation}

Lewis, K. K. (1995). Are Foreign Exchange Intervention and Monetary Policy Related and Does It Really Matter?. Journal of Business, 68 (2), 185-214. Retrieved from http://repository.upenn.edu/fnce_papers/226 


\title{
Are Foreign Exchange Intervention and Monetary Policy Related and Does It Really Matter?
}

\begin{abstract}
The relationship between foreign exchange intervention and monetary policy underlies the question of whether sterilized interventions can affect the exchange rate. In this article, I examine this relationship using data on U.S. foreign exchange interventions from 1985 to 1990, recently made publicly available. I examine whether interventions could be viewed as "signaling" changes in future monetary policy variables. I also consider whether changes in monetary policy may induce interventions in an effort by central bankers to " lean against the wind" of exchange rate movements. Interestingly, I find evidence both that interventions help predict monetary policy variables and that monetary variables help predict interventions.
\end{abstract}

\author{
Disciplines \\ Economics | Finance | Finance and Financial Management
}




\section{Are Foreign Exchange Intervention and Monetary Policy Related, and Does It Really Matter?*}

Over the last 2 decades, the question of how sterilized interventions can affect the exchange rate has been the focus of a great deal of attention in both academic and policy-making circles. Central to this debate has been the observation that sterilized interventions do not alter the relative money supplies of countries and therefore should not have any obvious effect on the exchange rate. In the 1970 s and early 1980 s, it was thought that these interventions might affect the exchange rate through a "portfolio balance" channel. Subsequent empirical research has found this story to be highly implausible, however. ${ }^{1}$

An alternative possibility, suggested by Mussa (1981), is that intervention may signal changes in future monetary policy. This explanation would say that central banks may signal a more contractionary future monetary policy by buying domestic currency in the foreign exchange market today. Therefore, the expectations of future tighter

\footnotetext{
* I am grateful to Hans Genberg and an anonymous referee for comments, to Hyungdo Ahn for research assistance, and to Ralph Smith for the intervention data as well as useful conversations about the conduct of intervention policy. Any errors are mine alone.

1. For example, Rogoff (1984), Lewis (1988), and others as surveyed in Edison (1992) find no evidence of a portfolio balance channel. However, Dominguez and Frankel (1993) find some support for this channel under the assumptions that an international capital asset pricing model holds and that exchange rate expectations can be measured with survey data.
}

(Journal of Business, 1995, vol. 68, no. 2)

(c) 1995 by The University of Chicago. All rights reserved. 0021-9398/95/6802-0002\$01.50
The relationship between foreign exchange intervention and monetary policy underlies the question of whether sterilized interventions can affect the exchange rate. In this article, I examine this relationship using data on U.S. foreign exchange interventions from 1985 to 1990 , recently made publicly available. I examine whether interventions could be viewed as "signaling" changes in future monetary policy variables. I also consider whether changes in monetary policy may induce interventions in an effort by central bankers to "lean against the wind" of exchange rate movements. Interestingly, I find evidence both that interventions help predict monetary policy variables and that monetary variables help predict interventions. 
monetary policy will make the exchange rate appreciate, even though the monetary effects of the intervention are currently offset. Since this signaling story was first proposed, a number of academic studies have emphasized it, and Federal Reserve publications have even claimed signaling to be a reason for and against intervening. ${ }^{2}$

If intervention provides a signal of future monetary policy, then the intervention should indeed be followed by changes in monetary policy variables. Therefore, in this article, I ask whether interventions help predict changes in monetary policy by examining the relationship between intervention and monetary policy variables. ${ }^{3}$ Despite the obvious importance of this issue, its direct analysis has only recently been made possible by the release of actual intervention data to the public.

In Section I, I begin with an illustrative example of how intervention can affect the exchange rate through changing expectations of future monetary policy. I then test this relationship with Granger-causality tests of intervention on various U.S. monetary policy variables. These monetary policy variables include M1, monetary base, nonborrowed reserves, and the Federal Reserve (Fed) funds rate, as well as the differential between the Fed funds rate relative to some foreign interest rates. For many cases, there is a significant relationship between intervention and changes in monetary aggregates. However, innovations to intervention are generally correlated with changes in monetary aggregates only within a short 2-week period. Furthermore, the coefficients relating intervention to future monetary policy are often the wrong sign to be consistent with the signaling story.

I therefore ask in Section II whether intervention is instead a response to economic conditions as reflected in the monetary variables. In this case, all of the variables except monetary base appear to explain intervention. These basic results continue to hold when intervention is treated as a limited dependent variable. Again, however, these relationships are strongest within a 2-week period.

One reason why intervention and monetary policy may be correlated during the 2-week period is the way in which sterilized intervention takes place. Section III describes how the nature of the Federal Reserve operating procedures together with foreign exchange interven-

2. For empirical studies discussing signaling, see Dominguez (1987) as well as other references in Edison (1992). Signaling has been used as a reason against intervention at Federal Open Market Committee (FOMC) meetings (e.g., the minutes of FOMC meeting, August 22, 1989, in Federal Reserve Board 1989).

3. While I use actual intervention data, Kaminsky and Lewis (1993) use market observations of days when central banks were intervening to test whether market participants would have considered intervention to be a signal. We used these observations to estimate a regime-switching process for money supply. In a similar vein, Klein and Rosengren $(1991,1992)$ examine the relationship between market observations of intervention and discount rate changes by the Group of Three countries. 
tion can induce a lag between intervention and sterilization, particularly during 2-week intervals corresponding to required reserves accounting periods. When the Granger-causality tests are performed after lagging intervention by 1-2 weeks, there is no longer much evidence that intervention helps predict monetary aggregates.

In Section IV, I consider whether a correlation between intervention and monetary policy would help explain the exchange rate anyway. That is, the signaling story presumes that changes in the money supply in fact affect the exchange rate, while empirical studies have found little evidence that money supply changes are statistically related to the exchange rate. ${ }^{4}$

These findings mirror early empirical findings that money supply innovations induce a positive or insignificant effect on the interest rate. ${ }^{5}$ These findings have recently been criticized on the grounds that broad monetary aggregates typically used by the early studies contain a significant component that is not under the control of the Federal Reserve. Christiano and Eichenbaum (1991, 1992a, 1992b) argue that nonborrowed reserves provide a better measure of money supply innovations. By contrast, Bernanke and Blinder (1992) propose the Federal funds rates as a monetary policy indicator and find that this measure is a better predictor of real economic activity than any monetary aggregate.

This debate suggests a reexamination of the monetary policy shock and exchange rate relationship as well. Broader monetary aggregates may include money demand shocks that are inappropriate for evaluating the effects of money supply innovations on the exchange rate. Therefore, in this article, I ask whether nonborrowed reserves or Fed funds rates provide different implications than M1 for this relationship. I address this question by estimating the impulse response functions of the deutsche mark (DM)/dollar and the yen/dollar exchange rates arising from these monetary shocks. Interestingly, I find that the monetary variables affect the exchange rates in the expected direction. These results provide new evidence as well as new questions about the relationship between exchange rates, monetary variables, and intervention. I conclude by noting the limitations of these results and pointing to some important directions for future research.

\section{Does Intervention Help "Signal” Future Monetary Variables?}

The "signaling hypothesis" states that interventions induce traders in the market to alter their expectations of future monetary policy. This

4. See, e.g., Meese and Rogoff (1983). In contrast, Mark (1993) finds a significant relationship between money supplies and exchange rates over long horizons.

5. See, e.g., Mishkin $(1981,1982)$ and the references in Christiano and Eichenbaum (1991). 
hypothesis requires that interventions are in fact related to monetary variables in a systematic way. In this section, I first provide a simple example to illustrate what people may mean when they talk about this hypothesis. I then present evidence on the relationship between intervention and monetary policy.

\section{A. A Simple Example of the Signaling Hypothesis}

Consider a standard asset-pricing model

$$
s_{t}=(1-\theta) \sum_{J=0}^{\infty} \theta^{j} E_{t} f_{t+j}
$$

where $s$ is the log exchange rate, $f$ is the log of "fundamentals," and $\theta$ is a discount factor. In monetary models of the exchange rate, $\theta=$ $\alpha /(1+\alpha)$, where $\alpha$ is the semielasticity of money demand. ${ }^{6}$ More specifically, let $f_{t}$ be given by

$$
f_{t}=\left(m_{t}-m_{t}^{*}\right)+v_{t},
$$

where $m$ and $m^{*}$ are the domestic and foreign monetary policy variables and $v$ measures other fundamentals out of the control of the monetary authorities.

For simplicity, I will assume that $m^{*}$ and $v$ are exogenous and are mutually uncorrelated. In this case, it can be shown that the exchange rate solution is composed of two components. The first component depends on the expectations of future domestic money, $m$. The second component depends on current expectations of future values of $m^{*}$ and $v .^{7}$ To focus on the role of monetary shocks, I will subsume the effects of $v$ and $m^{*}$ by setting their values equal to zero so that $f_{t}=$ $m_{t}$. This assumption implies that the effects of future expectations about these variables will be ignored. However, setting these variables equal to zero does not lose generality for studying the effects of intervention and domestic money on exchange rates since future expectations of $v$ and $m^{*}$ are by assumption independent of $m$ and $n$.

To correspond roughly with the empirical analysis above, I will treat the process of fundamentals as autoregressive in first differences:

$$
\Delta m_{t}=\rho_{m} \Delta m_{t-1}+\beta n_{t-k}+u_{t},
$$

where $\Delta$ is the backward difference operator, $\rho_{m}$ is the autoregressive coefficient of fundamentals differences on their own lag, $n_{t}$ is foreign exchange intervention at time $t$, and $\beta$ is a parameter relating intervention $k$ periods in the past with a current change in money supply. The variable $n$ is measured as purchases of domestic currency (sales of

6. See, e.g., Frenkel and Mussa (1980) and Mussa (1982).

7. See the discussion in Lewis (1989). 
foreign currency) by the central bank. If the central bank is "signaling", with interventions that are consistent with subsequent changes in money supplies, then an increase in $n$ at $t-k$ will be correlated with a decrease in $m$ in the future at time $t$. Therefore, $\beta$ would be negative.

Calculating the expectations in the exchange rate equation (1) requires a process for intervention. In keeping with the autoregressive structure above, this process is assumed to follow: ${ }^{8}$

$$
n_{t}=\rho_{n} n_{t-1}+e_{t}
$$

where $E\left(e_{t} u_{t}\right)=0$.

For a general lag $k$ at which intervention signals monetary policy, the exchange rate solution can be represented as

$$
\mathrm{s}_{t}=m_{t-1}+\delta_{m}\left(\Delta m_{t}-\beta n_{t-k}\right)+\beta \delta_{m} \sum_{j=0}^{\infty} \theta^{j} E_{t} n_{t-k+j},
$$

where $\delta_{m} \equiv\left(1-\theta \rho_{m}\right)^{-1}$. The exchange rate depends on three components: the lagged money supply level, the discounted present value of the change in the money supply adjusted for the effects of lagged intervention, and the expected discounted present value of all future interventions. In particular, the current change in the money supply less intervention effects is discounted by $\delta_{m}$, giving the present value of the effects of the current monetary policy change on all future periods. The effects of all future intervention on the exchange rate is also discounted by the monetary effects on all future periods as measured by $\delta_{m}$.

As equation (5) shows, current interventions affect the exchange rate according to how they alter the expectations of future money supplies and thereby the exchange rate. This effect depends upon the parameter $\beta$. Note that when $\beta$ equals zero, then according to equation (3), intervention conveys no information about future money supply changes. In this case, the last term in equation (5) shows that intervention has no effect on the exchange rate. In contrast, when expected dollar purchases as measured by increases in $n$ signal future reductions in monetary policy, then $\beta$ is negative. In this case, current and expected future dollar purchases will lead to dollar appreciation today.

To consider a more concrete example, suppose that the lag between interventions of dollar purchases and changes in the money supply is 1 period, so that $k=1$. In this case, the exchange rate solution is

$$
s_{t}=m_{t-1}+\delta_{m} \Delta m_{t}+\beta \theta \delta_{m} \delta_{n} n_{t},
$$

8. This process treats intervention as a continuous process for simplicity. As will be seen below, there are many days in the data when no intervention occurs, however. Kaminsky and Lewis (1993) treat the occurrence of intervention as affecting the future money supply relative to its level in the absence of intervention. 
where $\delta_{m} \equiv\left(1-\theta \rho_{n}\right)^{-1}$. Clearly, a current intervention $n_{t}$ will affect the exchange rate in the direction implied by the signaling story as long as $\beta<0$. In this case, an increase in current dollar purchases will increase the expected money supplies next period and thereby the exchange rate through the discount rate of money on the exchange rate, $\theta$. The present value of this effect on all future expected intervention levels, and therefore money supplies, is measured by the product of the discount factors of money, $\boldsymbol{\delta}_{m}$, and of intervention, $\boldsymbol{\delta}_{n}$.

If the lag between intervention and money supply changes, $k$, is longer than 1 period, then the example becomes more complicated but these basic features remain. The longer is $k$, the farther in the future current interventions are expected to affect the money supply and, therefore, the less impact interventions will have on the exchange rate today.

\section{B. Interventions and Monetary Policy Measures}

I now examine whether intervention helps predict future changes in monetary policy. The intervention series are daily interventions by the Federal Reserve from 1985 to 1990 . The U.S. monetary policy variables studied are M1, monetary base, nonborrowed reserves, and the Fed funds rate. These data are available at different frequencies. The shortest frequency of the Fed funds rate is daily, and that of M1 is weekly, but monetary base and nonborrowed reserves are available only biweekly. The Data Appendix (App. A) gives the sources of these variables.

Figure 1 shows some of these measures of monetary policy during the period of study. The top panel plots weekly observations of M1 money supply together with the Fed funds rate. As the picture shows, the growth rate of M1 accelerated during 1985 and 1986. At the same time, the Fed funds rate trended downward, in tandem with other interest rates. From mid-1984 to the end of 1986, most interest rates declined 5-6 percentage points. These downward movements were accommodated by two discount rate cuts in April and August 1986. Monetary policy was quite different during the period from 1987 through late 1988. Largely in response to an increase in inflation, the Federal Reserve began tightening reserves in the second quarter of 1987 , and as a result most of the monetary aggregates rose at much smaller rates. The top panel of figure 1 shows the sharp deceleration in the growth rate of M1 as well as the upward trend in the Fed funds rate extending into 1988. This tightening of monetary policy was accentuated with discount rate increases in October 1987, August 1988, and February 1989.

Recent empirical studies have emphasized that movements in broad monetary aggregates such as M1 can be misleading measures of mone- 

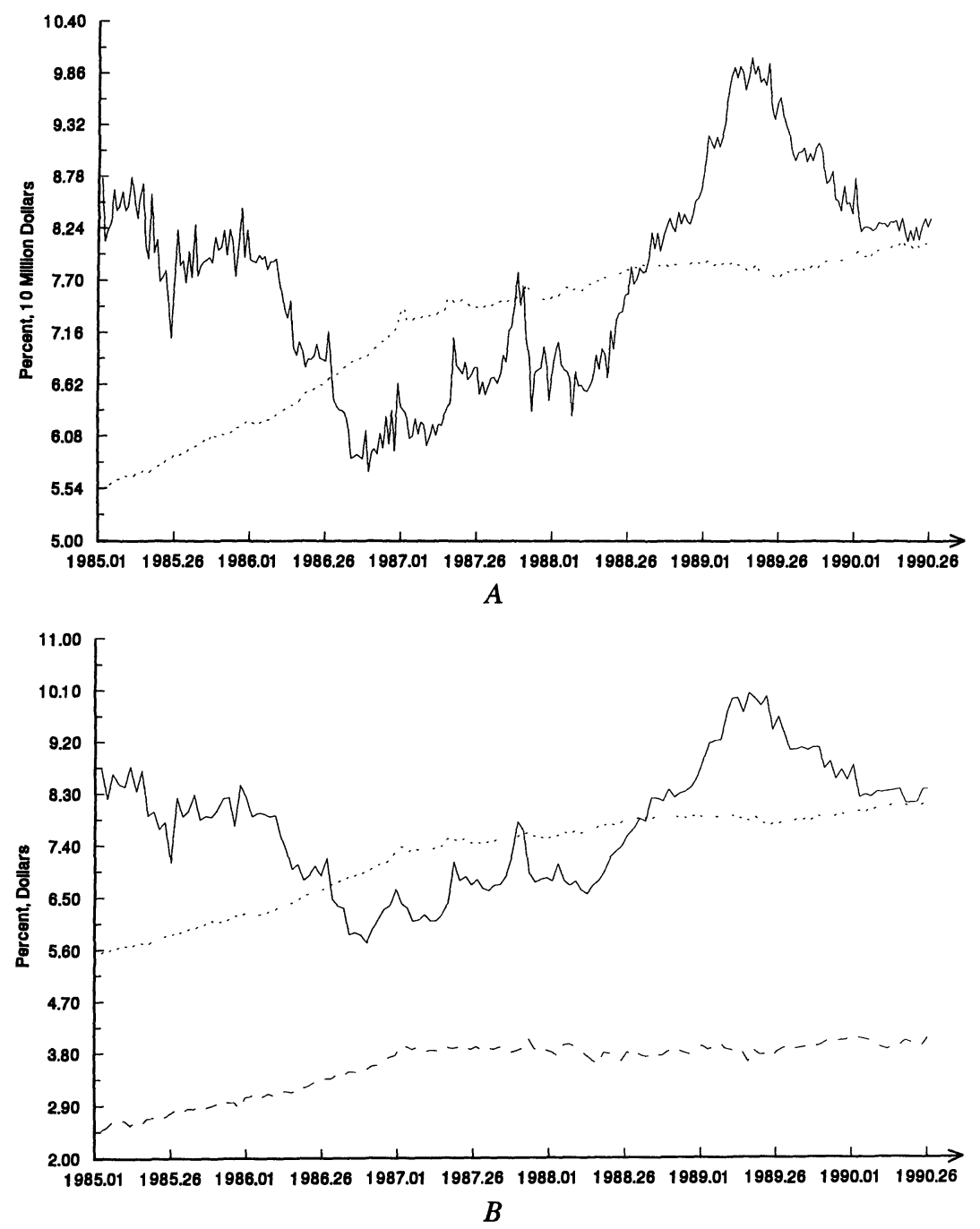

FIG. 1.-Relationship between monetary variables. $A$, weekly series. M1 = dotted line; Fed funds = solid line. $B$, biweekly series. $M 1=$ dotted line; Fed funds $=$ solid line; Nonborrowed reserves $=$ dashed line. Note. - M1 is in $\$ 10$ million units. Nonborrowed reserves are in $\$ 1$ million units.

tary policy, relative to nonborrowed reserves. Panel B of figure 1 depicts nonborrowed reserves against M1 and Fed funds, observed only biweekly.

\section{Are Interventions Related to U.S. Monetary Policy Variables?}

To test whether intervention helps predict these monetary policy variables, bivariate vector autoregressions (VARs) were estimated for 
each monetary variable and intervention. In other words, equations were estimated for the systems

$$
\left[\Delta M(i)_{t}, n_{t}\right]^{\prime}=B(L)\left[\Delta M(i)_{t}, n_{t}\right]^{\prime}+\epsilon_{t},
$$

and

$$
E\left(\epsilon_{t} \epsilon_{t}^{\prime}\right)=V
$$

where $M(i)$ is the monetary aggregate for $i=\mathrm{M} 1$, monetary base (MB), nonborrowed reserves (NBR), or Fed funds (FF); where $B(L)$ is a polynomial matrix in the lag operator, $L$; and where $\epsilon_{t}$ is a bivariate independently and identically distributed (i.i.d.) random variable with mean vector zero. ${ }^{9}$

In order to combine intervention and monetary aggregates at different frequencies, several intervention series were formed. First, since M1 is measured from Monday to Monday, the daily intervention series were cumulated over the same period. These data together with Monday Fed funds rates were used as the weekly frequency data series. Second, since monetary base and nonborrowed reserves are measured Wednesday to the second following Wednesday, a second intervention series was cumulated over the same period. These data were used as the biweekly frequency data series. ${ }^{10}$

The maximum lag length of these VARs was first tested with a Wald test of zero restrictions at each lag. As reported in Appendix table B1 these lag lengths were quite short. Except for the monetary base, the maximum lag length of these VARs were 2 weeks or less.

Panel A of table 1 reports the results of Granger-causality tests of intervention on the monetary policy variables. ${ }^{11}$ Interestingly, the hypothesis that intervention does not help predict monetary policy at the biweekly frequency is rejected at the $90 \%$ confidence level for three of the four monetary measures. Furthermore, intervention is significantly related to the Fed funds rate at the weekly frequency.

For the signaling story to be right, the coefficient on lagged intervention should indicate that dollar purchases are correlated with contractionary monetary policy. When monetary policy is measured by monetary aggregates, the coefficient on lagged intervention should be negative. When this policy is measured by Fed funds, dollar purchases should raise the interest rate, so that the lagged intervention coefficient should be positive.

9. Note that first-differencing the monetary aggregates in the VAR imposes the condition that intervention is a stationary variable.

10. M1 and Fed funds were also used with this series. Experimentation with cumulating intervention with M1 from Monday to the second Monday and using Wednesday Fed funds rates did not alter the basic conclusions below.

11. It should be noted that, while I use the standard terminology of "causality," the usual caveat applies here that correlation does not imply causality. 
TABLE 1 Granger-Causality Tests of Intervention on U.S. Monetary Variables and VAR Coefficients

A. Granger-Causality Tests

\begin{tabular}{lcccc}
\hline & \multicolumn{4}{c}{ Predicted Variables } \\
\cline { 2 - 5 } Frequency & $\Delta \mathrm{M} 1$ & $\Delta \mathrm{MB}$ & $\Delta \mathrm{NBR}$ & $\Delta \mathrm{FF}$ \\
\hline Daily & .306 & $\ldots$ & $\ldots$ & .318 \\
Weekly & .306 & .059 &. .9 & .006 \\
Biweekly & .093 & .059 & .843 & .053 \\
\hline
\end{tabular}

B. Coefficients on Lagged Intervention-Daily Frequency

\begin{tabular}{lccccccccc}
\hline & \multicolumn{10}{c}{ Lags } \\
\cline { 2 - 10 } Variable & 1 & 2 & 3 & 4 & 5 & 6 & 7 & 8 & 9 \\
\hline$\Delta \mathrm{FF}$ & -.02 & -.11 & .07 & .01 & .07 & .08 & -.09 & -.02 & .05 \\
& $(.07)$ & $(.11)$ & $(.06)$ & $(.05)$ & $(.05)$ & $(.06)$ & $(.07)$ & $(.05)$ & $(.05)$ \\
\hline
\end{tabular}

C. Coefficients on Lagged Intervention-Weekly Frequency

\begin{tabular}{lcc}
\hline & \multicolumn{2}{c}{ Lags } \\
\cline { 2 - 3 } Variable & 1 & 2 \\
\hline$\Delta \mathrm{M} 1$ & .305 & $\ldots$ \\
$\Delta \mathrm{FF}$ & $(.298)$ & $.007^{*}$ \\
& $-.002^{*}$ & $(<.001)$ \\
\hline
\end{tabular}

D. Coefficients on Lagged Intervention-Biweekly Frequency

\begin{tabular}{lcc}
\hline & \multicolumn{2}{c}{ Lags } \\
\cline { 2 - 3 } Variable & 1 & 2 \\
\hline$\Delta \mathrm{M} 1$ & .719 & $\ldots$ \\
$\Delta \mathrm{MB}$ & $(.428)$ & $-1.094^{*}$ \\
& .354 & $.512)$ \\
$\mathrm{NBR}$ & $(.633)$ & $\ldots$ \\
$\Delta \mathrm{FF}$ & -.015 & $\ldots$ \\
& $(.077)$ & \\
\hline
\end{tabular}

Note.-Panel A reports marginal significance levels of the hypothesis that all lagged coefficients of intervention equal zero in a projection of the column variable on lagged own variables and intervention. Lag lengths were chosen by estimating a vector autoregression (VAR) with a maximum of 10 lags and forming a Wald statistic that all lags greater than or equal to $k$ are zero, for $k=10,9, \ldots$ The first lag that rejected this restriction was used as the lag length. The covariance matrix was corrected for conditional heteroscedasticity using Newey and West (1987). These tests are reported in Appendix table B1. Panels B-D report coefficient estimates of VARs. The column variables are the first difference of monetary variables: $\mathrm{MB}=$ monetary base, NBR $=$ nonborrowed reserves, $\mathrm{FF}=$ Fed funds rate. Standard errors are in parentheses.

* Significant at the $95 \%$ confidence level. 
Panels B, C, and D of table 1 report at the daily, weekly, and biweekly frequencies, respectively, the coefficient estimates on lagged intervention for each of the measures of monetary policy. Panel B shows that daily intervention has no discernible relationship with changes in the Fed funds rate. Panel $\mathrm{C}$ demonstrates that the coefficient on lagged intervention for M1 and Fed funds is the opposite sign from the signaling story for a 1-week lag, although not for Fed funds at a 2-week lag. Panel D reports the coefficients at the biweekly frequency. For M1 and monetary base, the coefficients are again of the wrong sign at the first lag. However, the coefficient for monetary base at two lags is significantly of the sign predicted by the signaling story. The correlation between lagged intervention and Fed funds is again significant and, combining the effects of the first- and second-week lags, it is also positive.

Overall, the evidence in table 1 provides a mixed picture of the signaling story. Lagged intervention is significantly related to future changes in weekly and biweekly Fed funds rates and biweekly M1 and monetary base. However, the correlations are in the direction suggested by the signaling story only over biweekly Fed funds changes and monetary base changes.

\section{Are Interventions Related to Future Relative Monetary Policies?}

The theoretical example above illustrated that U.S. monetary policy relative to foreign monetary policy is the important variable for determining the exchange rate. Therefore, it may seem inappropriate to focus on U.S. monetary variables alone. Unfortunately, foreign money supply data are typically available only at a monthly frequency. Since the data sample is short, I cannot use monthly money supply data with much confidence.

As an alternative I considered the interest differentials between the United States and two countries, Germany and Japan. The German and Japanese call money rates were used to correspond to an overnight interbank rate, as is the Fed funds rate. These variables were then used instead of the U.S. monetary policy variables above to, first, test the lag lengths and then to conduct Granger-causality tests. The lag-length tests are reported in Appendix table B2. As with the U.S. monetary policy variables, the lag lengths are quite short. Except for the differential between the Fed funds rate and the German rate, the lag lengths were all 2 weeks more or less. ${ }^{12}$

Panel A of table 2 reports the results of Granger-causality tests of

12. The Fed funds/German rate appeared to be somewhat sensitive to the day of the week that the variables were sampled. When the series were sampled on Wednesdays instead of Mondays, the lag length was 1 week. The longer lag structure is used in the estimation results below in order to provide more conservative estimates. 
intervention on these interest differentials. However, the hypothesis that intervention provides no information concerning future interest differentials cannot be rejected in any case.

Panals B and C report the coefficients on lagged intervention in these VARs to see if they indicate any pattern between lagged intervention and future monetary policy. However, the signs are mixed, and most of the coefficient estimates are insignificantly different from zero.

\section{Do Monetary Variables Help “Signal” Intervention?}

An alternative view of the correlation between intervention and monetary policy is that central banks intervene to try to maintain a monetary policy that is consistent with their targets of the exchange rate. In this case, changes in monetary policy with domestic targets in mind may induce counterproductive movements in the exchange rate. These movements in the exchange rate may, in turn, induce central bankers to intervene in order to try to "lean against the wind."

Indeed, this type of behavior seemed to characterize Federal Reserve policy for periods during 1988-90. In particular, while monetary policy remained relatively contractionary well into 1989 , as noted above, the Federal Reserve intervened heavily to sell dollars for most of the period. Starting on June 27, 1988, the Federal Reserve sold dollars in the foreign exchange market, totalling $\$ 5$ billion by September 26. A second round of heavy dollar selling began on January 6 , 1989 , despite the fact that monetary policy remained relatively tight.

The conflict between the objectives to fight inflation by the Fed and to keep the dollar from strengthening, deemed desirable by the Treasury, became evident in meetings of the Federal Open Market Committee. During early 1989, debate increased among the governors on the Federal Reserve board concerning intervention carried out at the behest of the Treasury and the appropriateness of its signal toward monetary policy. By the FOMC meeting on May 16, 1989, intervention had become an important item of discussion as large purchases of foreign currency assets by the New York Federal Reserve Bank had increased its holdings beyond the legal limit. By the August 22 FOMC meeting, many governors were critical of the intervention policy. Governors Angell and Johnson dissented on a move that would allow further intervention stating "intervention confuses market participants concerning the policy commitment toward price stability" (minutes of FOMC meeting, August 22, 1989, in Federal Reserve Board 1989).

\section{A. Is There a Relationship between Monetary Policy and Future Interventions?}

As this discussion suggests, intervention and monetary policy may be related by a "leaning against the wind" policy in which monetary 
TABLE 2 Granger-Causality Tests of Intervention on Interest Differentials and VAR Coefficients

\section{A. Granger-Causality Tests}

\begin{tabular}{lcc}
\hline & \multicolumn{2}{c}{ Predicted Variables } \\
\cline { 2 - 3 } Frequency & $\mathrm{FF}-R^{\mathrm{Jpn}}$ & $\mathrm{FF}-R^{\mathrm{Ger}}$ \\
\hline Daily & .472 & .283 \\
Weekly & .120 & .581 \\
\hline
\end{tabular}

B. Coefficients on Lagged Intervention-Daily Frequency

\begin{tabular}{lcc}
\hline & \multicolumn{2}{c}{ Predicted Variables } \\
\cline { 2 - 3 } Lag & $\mathrm{FF}-R^{\mathrm{Jpn}}$ & $\mathrm{FF}-R^{\mathrm{Ger}}$ \\
\hline 1 & .066 & .073 \\
& $(.053)$ & $(.051)$ \\
2 & -.058 & -.031 \\
& $(.073)$ & $(.070)$ \\
3 & -.124 & -.118 \\
& $(.105)$ & $(.105)$ \\
4 & .054 & .059 \\
5 & $(.054)$ & $(.054)$ \\
& .012 & .000 \\
6 & $(.044)$ & $(.047)$ \\
& $.082^{*}$ & .079 \\
7 & $(.048)$ & $(.046)$ \\
8 & .053 & .055 \\
& $(.053)$ & $(.051)$ \\
9 & -.077 & -.073 \\
& $(.067)$ & $(.064)$ \\
& -.000 & .000 \\
& $(.056)$ & $(.056)$ \\
\hline
\end{tabular}

\section{Coefficients on Lagged Intervention-Weekly Frequency}

\begin{tabular}{lcc}
\hline & \multicolumn{2}{c}{ Predicted Variables } \\
\cline { 2 - 3 } Lag & $\mathrm{FF}-R^{\mathrm{Jpn}}$ & $\mathrm{FF}-R^{\mathrm{Ger}}$ \\
\hline 1 & -.091 & -.047 \\
& $(.048)$ & $(.042)$ \\
2 & .025 & .038 \\
3 & $(.053)$ & $(.061)$ \\
& $\cdots$ & .026 \\
& & $(.052)$ \\
\hline
\end{tabular}

Note.-Panel A reports marginal significance levels of the hypothesis that all lagged coefficients of intervention equal zero in a projection of the column variable on lagged own variables and intervention. Lag lengths were chosen by estimating a vector autoregression (VAR) with a maximum of 10 lags and forming a Wald statistic that all lags greater than or equal to $k$ are zero, for $k=10,9, \ldots$ The first lag that rejected this restriction was used as the lag length. The covariance matrix was corrected for conditional heteroscedasticity using Newey and West (1987). These tests are reported in Appendix table B2. Panels B and C report coefficient estimates of VARs. The column variables are $\mathrm{FF}=$ Fed funds rate, $R^{\mathrm{Jpn}}$ is the Japanese call money rate, and $R^{\mathrm{Ger}}$ is the German call money rate. Standard errors are in parentheses.

* Significant at the $90 \%$ level. 
policy helps predict future changes in intervention. To evaluate this possibility, table 3 reports marginal significance levels from Grangercausality tests of intervention on the monetary aggregates in each column. Interventions appear to be predictable at the biweekly frequency both from Fed funds rate changes and from nonborrowed reserves changes, although this relationship is less apparent from the broader monetary aggregates. In contrast, Fed funds rate changes at the higher frequencies of weekly and daily appear to contain no information about intervention changes.

As reported in table 4, this pattern is reversed when Grangercausality tests of Fed funds differentials with foreign rates are used instead. In this case, weekly changes in interest differentials of the Fed funds against the Japanese and German call money rates provide no information about interventions. However, daily movements in these differentials appear to predict intervention movements, particularly for the Japanese case.

Overall, movements in Fed funds and nonborrowed reserves appear

TABLE 3 Granger-Causality Tests of U.S. Monetary Variables on Intervention

\begin{tabular}{lcccc}
\hline & \multicolumn{4}{c}{ "Causal" Variables } \\
\cline { 2 - 5 } Frequency & $\Delta \mathrm{M} 1$ & $\Delta \mathrm{MB}$ & $\Delta \mathrm{NBR}$ & $\Delta \mathrm{FF}$ \\
\hline Daily &. .693 & $\ldots$ & $\ldots$ & .113 \\
Weekly & .093 & .635 & .020 & .615 \\
Biweekly & .090 & .635 & .027 \\
\hline
\end{tabular}

Note. - The table reports marginal significance levels of the hypothesis that all coefficients on lags of the column variable equal zero in a projection of intervention on lagged intervention and lags of the column variable. Lag lengths were chosen by estimating a vector autoregression (VAR) with a maximum of 10 lags and forming a Wald statistic that all lags greater than or equal to $k$ are zero, for $k=10,9, \ldots$. The first lag that rejected this restriction was used as the lag length. The covariance matrix was corrected for conditional heteroscedasticity using Newey and West (1987). These tests are reported in Appendix table B1. The column variables are the first difference of monetary variables: $\mathrm{MB}=$ monetary base, $\mathrm{NBR}=$ nonborrowed reserves, $\mathrm{FF}=$ Fed funds rate.

TABLE 4 Granger-Causality Tests of Interest Differentials on Intervention

\begin{tabular}{lcc}
\hline & \multicolumn{2}{c}{ "Causal” Variables } \\
\cline { 2 - 3 } Frequency & $\mathrm{FF}-R^{\mathrm{jpn}}$ & $\mathrm{FF}-R^{\mathrm{Ger}}$ \\
\hline Daily & .016 & .077 \\
Weekly & .283 & .615 \\
\hline
\end{tabular}

NoTE.-The table reports marginal significance levels of the hypothesis that all coefficients on lags of the column variable equal zero in a projection of intervention on lagged intervention and lags of the column variable. Lag lengths were chosen by estimating a vector autoregression (VAR) with a maximum of 10 lags and forming a Wald statistic that all lags greater than or equal to $k$ are zero, for $k=10,9, \ldots$. The first lag that rejected this restriction was used as the lag length. The covariance matrix was corrected for conditional heteroscedasticity using Newey and West (1987). These tests are reported in Appendix table B2. The column variables are FF $=$ Fed funds rate, $R^{\mathrm{Jpn}}$ is the Japanese call money rate, and $R^{\mathrm{Ger}}$ is the German call money rate. 
to be useful for predicting intervention at longer horizons of 2 weeks, while interest differentials are useful for predicting intervention at intervals less than a week.

\section{B. Treating Intervention as a Limited Dependent Variable}

The analysis above treated intervention as a continuous random variable since it can take any value on the real line. However, there were many days in which no intervention occurred, so that much of the distribution of intervention observations is concentrated at zero. The errors from regressions of intervention on other variables may therefore be far from normally distributed in small samples. For this reason, I also treat intervention as a limited dependent variable that is a function of lagged monetary policy variables.

Intervention was classified into three cases defined as follows:

$$
\begin{array}{ll}
I_{t}=0 & \text { no intervention, } \\
I_{t}=-1 & \text { dollar sales, } \\
I_{r}=1 & \text { dollar purchases. }
\end{array}
$$

Using this measure of intervention, the probability of intervention was treated as a logistic probability function given by

$$
\begin{gathered}
\operatorname{prob}\left(I_{t}=0\right)= \\
\frac{\exp \left[g_{0}+\sum_{\ell=1}^{k} g_{\ell} \Delta M(i)_{t-\ell}\right]}{1+\exp \left[g_{0}+\sum_{\ell=1}^{k} g_{\ell} \Delta M(i)_{t-\ell}\right]+\exp \left[c_{0}+\sum_{\ell=1}^{k} c_{\ell} \Delta M(i)_{t-\ell}\right]} \\
\frac{\operatorname{prob}\left(I_{t}=-1\right)=}{\exp \left[c_{0}+\sum_{\ell=1}^{k} c_{\ell} \Delta M(i)_{t-\ell}\right]} \\
1+\exp \left[g_{0}+\sum_{\ell=1}^{k} g_{\ell} \Delta M(i)_{t-\ell}\right]+\exp \left[c_{0}+\sum_{\ell=1}^{k} c_{\ell} \Delta M(i)_{t-\ell}\right]
\end{gathered}
$$

and

$$
\frac{\operatorname{prob}\left(I_{t}=1\right)=}{1+\exp \left[g_{0}+\sum_{\ell=1}^{k} g_{\ell} \Delta M(i)_{t-\ell}\right]+\exp \left[c_{0}+\sum_{\ell=1}^{k} c_{\ell} \Delta M(i)_{t-\ell}\right]}
$$


where $M(i)$ is the monetary variable; $i=\mathrm{M} 1, \mathrm{MB}, \mathrm{NBR}, \mathrm{FF}$, as before; and $k$ is the maximum lag in the vector autoregression estimated above for each bivariate system.

The intuition behind these equations can be seen more readily by taking the logarithms of these probabilities, forming the odds ratios, and focusing on the case where $k=1$ :

$$
\begin{gathered}
\log \left[\operatorname{prob}\left(I_{t}=-1\right) / \operatorname{prob}\left(I_{t}=1\right)\right]=c_{0}+c_{1} \Delta M(i)_{t-1}, \\
\log \left[\operatorname{prob}\left(I_{t}=0\right) / \operatorname{prob}\left(I_{t}=1\right)\right]=g_{0}+g_{1} \Delta M(i)_{t-1},
\end{gathered}
$$

and

$\log \left[\operatorname{prob}\left(I_{t}=-1\right) / \operatorname{prob}\left(I_{t}=0\right)\right]=\left(c_{0}-g_{0}\right)+\left(c_{1}-g_{1}\right) \Delta M(i)_{t-1}$.

Now suppose that large increases in monetary variables induce a depreciation in the currency and, thus, a dollar purchase intervention in response. If the Fed is "leaning against the wind," an increase in $\Delta M(i)$, for $i=\mathrm{M} 1, \mathrm{MB}$, and NBR will increase the probability of a dollar purchase intervention $\left(I_{t}=1\right)$ relative to a dollar sale intervention $\left(I_{t}=-1\right)$, so that we would expect $c_{1}<0$. Similarly, the increase in $M(i)$ should increase the probability of a dollar purchase intervention relative to no intervention in $(8 \mathrm{~b})$, so that $g_{1}<0$. Finally, the increase in $M(i)$ may decrease the probability of a dollar sale intervention in (8c) relative to no intervention, so that $c_{1}-g_{1}<0$. For the Fed funds rate as the dependent variable, a similar relationship applies, but with the opposite sign.

The constant coefficients in (8) have a similarly intuitive interpretation. If there is no change in the money supply, so that $\Delta M(i)=0$, then the probabilities are simply

$$
\begin{aligned}
\operatorname{prob}\left(I_{t}=0\right) & =\exp \left(g_{0}\right) /\left[1+\exp \left(g_{0}\right)+\exp \left(c_{0}\right)\right], \\
\operatorname{prob}\left(I_{t}=-1\right) & =\exp \left(c_{0}\right) /\left[1+\exp \left(g_{0}\right)+\exp \left(c_{0}\right)\right],
\end{aligned}
$$

and

$$
\begin{aligned}
\operatorname{prob}\left(I_{t}=1\right) & =\exp (0) /\left[1+\exp \left(g_{0}\right)+\exp \left(c_{0}\right)\right] \\
& =1 /\left[1+\exp \left(g_{0}\right)+\exp \left(c_{0}\right)\right] .
\end{aligned}
$$

Thus, the relationship between $g_{0}, c_{0}$, and zero indicates the probabilities of each intervention type when the monetary aggregate does not change.

Table 5 reports the results of estimating the logistic probabilities for each monetary aggregate examined in tables 1 and 3 . As column 1 shows, movements in M1 are significant explanatory variables for the probability of intervention. Interestingly, both $c_{1}$ and $g_{1}$ are negative, as predicted by the "leaning against the wind" explanation. However, $c_{1}-g_{1}>0$, so that the increase in $M(i)$ increases the probability of a dollar sale intervention relative to no intervention. 
TABLE 5 Logistic Probability Estimates of Intervention

\begin{tabular}{lccccccc}
\multicolumn{1}{c}{$\log \left[\operatorname{prob}\left(I_{t}=-1\right) / \operatorname{prob}\left(I_{t}=1\right)\right]=c_{0}+\sum_{\ell=1}^{k} c_{\ell} \Delta M(i)_{t-\ell}$} \\
\multicolumn{1}{c}{$\log \left[\operatorname{prob}\left(I_{t}=-1\right) / \operatorname{prob}\left(I_{t}=0\right)\right]=g_{0}+\sum_{\ell=1}^{k} g_{\ell} \Delta M(i)_{t-\ell}$} \\
\hline$\Delta M(i)$ & $c_{0}$ & $g_{0}$ & $c_{1}$ & $g_{1}$ & $c_{2}$ & $g_{2}$ & $\%$ Predicted \\
\hline M1 & $.734^{*}$ & $1.320^{*}$ & $-.122^{* *}$ & $-.152^{* *}$ & $\ldots$ & $\ldots$ & 52.3 \\
& $(.206)$ & $(.192)$ & $(.073)$ & $(.068)$ & & & \\
MB & $.959^{*}$ & $1.429^{*}$ & $-.249^{* *}$ & $-.236^{*}$ & -.175 & -.187 & 50.0 \\
NBR & $(.334)$ & $(.319)$ & $(.127)$ & $(.120)$ & $(.129)$ & $(.122)$ & 53.5 \\
& $.559^{*}$ & $1.138^{*}$ & .188 & .283 & $\ldots$ & $\ldots$ & 53.5 \\
FF & $(.247)$ & $(.226)$ & $(.382)$ & $(.351)$ & .130 & .032 & 64.3 \\
& $.456^{*}$ & $1.534^{*}$ & .073 & -.012 & .130 & $(.153)$ & \\
\hline
\end{tabular}

NotE.-Standard errors are in parentheses. The frequencies of the estimates are M1, weekly; MB, biweekly; NBR, biweekly; and FF, weekly.

* Significantly different from zero at the $95 \%$ confidence level.

$* *$ Significantly different from zero at the $90 \%$ confidence level.

The first lag of monetary base also suggests "leaning against the wind" behavior. Both $c_{1}$ and $g_{1}$ are significantly negative. Furthermore, in this case, $c_{1}-g_{1}$ is also negative, consistent with the view that increases in the monetary base reduce the probability of dollar sales interventions relative to no intervention. However, the second lags do not appear to affect significantly the likelihood of intervention.

Despite the significant effects of M1 and monetary base, neither nonborrowed reserves nor Fed funds appear to affect the probability of intervention. This pattern reverses the finding in table 3, where M1 and monetary base did not predict the intervention variable, while Fed funds and nonborrowed reserves did. A reason may be that the logit estimation focuses on whether intervention occurs, while the Grangercausality tests in table 3 analyze the magnitudes of intervention. Variations in the endogenous components in M1 and monetary base may affect the decision to intervene, while movements in the monetary policy variables such as nonborrowed reserves and Fed funds may influence the magnitudes of intervention.

\section{Is the Operating System Responsible?}

A feature of the relationship between intervention and monetary aggregates found above is that the maximum lags in the vector autoregressions are typically 2 weeks. Of course, while an autoregressive process implies that shocks today persist indefinitely, moving average processes with innovations that disappear at fixed lags can look much like autoregressive processes. Thus, the relationships found above suggest 
a possible alternative explanation for the apparent correlation between monetary variables and intervention.

To understand this explanation, it is necessary to examine the operating system of the Federal Reserve together with intervention operations. The domestic monetary policy is based on a borrowed reserves targeting procedure. Under this procedure, the FOMC selects a level of borrowed reserves to be used as an operating target, based on an assumed relationship between the Fed funds rate and borrowed reserves. On a day-to-day basis, open market operations are primarily guided by an interim target for nonborrowed reserves based on an estimated demand for total reserves (subtracting out the borrowed reserves component). The nonborrowed reserves target is changed on a daily basis as revised estimates of required reserves are received and, less frequently, as excess reserve estimates are reviewed. ${ }^{13}$

Foreign exchange intervention affects the supply of nonborrowed reserves when the Federal Reserve receives payment by debiting the reserve account of a purchasers' depository institution. However, this intervention does not affect nonborrowed reserves targets. ${ }^{14}$ Depending on the elasticity of short-term reserves demand, the institution of the purchaser of foreign exchange can either allow its dollar reserve level to fall temporarily or else try to increase the reserve level to its former level. If the banking system as a whole is willing to allow reserves to fall in the short run, then the intervention may not be effectively sterilized immediately. However, given the biweekly accounting for required reserves, the demand for reserves will likely return to its previous level over the 2-week period.

As a result of this complicated interaction of shocks to reserve supply induced by foreign exchange intervention and short-run demand for reserves, the effects of intervention on reserves may not be completely sterilized immediately. Rather, sterilization may occur only over time as the demand for reserves returns to its previous level.

If this story holds true, then the relationship between monetary aggregates and intervention during 2-week intervals may reflect in part the evolution of reserve demand. In this case, the correlations between monetary aggregates and intervention may have nothing to do with intentional signaling by the Federal Reserve.

As a simple check on this possibility, the vector autoregressions in tables 1 and 3 were repeated, after lagging intervention by 1 period. If

13. It should be noted, however, that the nature of the operating procedure changed during the sample period. Since late 1987, the Federal Reserve trading desk has adopted a more flexible approach to pursuing the borrowing objective, due to a striking instability in the behavior of borrowed reserves during that year. See Federal Reserve Board (1991).

14. The Open Market Operations desk uses this information to update its forecasts of reserves on the settlement date. For most currencies, settlement takes place 2 days from agreeing to buy or sell foreign exchange. 
TABLE 6 Granger-Causality Tests between U.S. Monetary Variables and Intervention Lagged 1 Period

\begin{tabular}{|c|c|c|c|c|}
\hline Frequency & $\Delta \mathrm{M} 1$ & $\Delta \mathrm{MB}$ & $\Delta \mathrm{NBR}$ & $\Delta \mathrm{FF}$ \\
\hline \multicolumn{5}{|c|}{ A. Predicted variables: } \\
\hline Weekly & .424 & $\cdots$ & . & .006 \\
\hline Biweekly & .893 & .084 & .708 & .128 \\
\hline \multicolumn{5}{|c|}{ B. "Causal" variables: } \\
\hline Weekly & .255 & & . . & .615 \\
\hline Biweekly & .893 & .707 & .341 & .367 \\
\hline
\end{tabular}

Note.-The table reports marginal significance levels for the hypothesis that lagged coefficients of intervention are zero in a projection of the column variable for panel A and for the hypothesis that lagged coefficients of the column variable are zero in a projection of intervention for panel $B$. See notes in tables 1 and 3 concerning lag lengths.

the relationships between intervention and money are due to the nature of the operating system, then lagging intervention will increase the likelihood that the sterilization process has been completed.

Table 6 reports these results. As the table shows in panel A, the hypothesis that intervention does not Granger cause monetary variables cannot be rejected at the $95 \%$ confidence level for any variable except the Fed funds rate at a weekly frequency. Also, as reported in panel B, the hypothesis that monetary variables do not Granger cause intervention cannot be rejected for any of the monetary variables.

Although this evidence is only suggestive, it supports the notion that the correlation between intervention and monetary aggregates may arise from a timing lag in the sterilization process.

\section{Does It Matter Anyway?}

To this point, I have examined the relationship between intervention and monetary aggregates. The evidence indicates both that intervention helps predict changes in monetary aggregates and that monetary aggregates help predict intervention. Once intervention is lagged 1 period to help reduce the likelihood that the sterilization of the intervention has not been completed, intervention continues to help explain Fed funds movements. However, none of the monetary variables help explain intervention. This evidence suggests that intervention may indeed help explain future movements in monetary policy, at least as characterized by Fed funds movements.

I now consider a more basic question: does it matter if intervention explains monetary indicators? In the simple example described in Section I, intervention moves the exchange rate because its relationship with future monetary policy induces traders to revise their forecasts of future monetary variables, and these monetary variables affect the exchange rate. This signaling story relies on the underlying presumption that money matters for determining the exchange rate.

Although all standard theoretical models use monetary variables as 
key ingredients of exchange rate determination, empirical examination has found little evidence of such a relationship. Thus, an important question is, Does it really matter?

\section{A. Does the Exchange Rate Really Depend on U.S. Monetary Variables?}

To address this question, I estimated bivariate VARs of U.S. monetary policy variables together with the German DM/dollar rate and the Japanese yen/dollar rate and examined the impulse response functions of exchange rates to the monetary variable. Given the recent debate on the monetary transmission mechanism, it is interesting to compare the effects of different monetary indicators. I therefore examine the impulse response functions from three different measures of monetary policy.

M1 has been the most frequently used measure of money supply in previous studies. For comparison with these studies, the first monetary variable used is M1.

The second monetary variable is motivated by the recent debate concerning the appropriate measure of monetary policy. Christiano and Eichenbaum $(1992 a, 1992 b)$ argue that early studies of the relationship between interest rates and money supplies were incorrect because they used M1 and other broad measures of monetary aggregates. Both of these aggregates include borrowed reserves that are positively correlated with the Fed funds rate and other interest rates since increases in these rates induce banks to borrow more at the discount window. Although borrowed reserves are a very small component of M1 and monetary base, they display considerable variability. As a result, M1 is frequently found to be positively correlated with interest rates, while subtracting out borrowed reserves gives a negative relationship with interest rates. Christiano and Eichenbaum find that when nonborrowed reserves are used as monetary measures instead of M1 or monetary base, then innovations to nonborrowed reserves imply negative responses of interest rates, as a liquidity channel would suggest.

If $\mathrm{M} 1$ contains a significant component that varies positively with interest rates, then this variable may also be inappropriate for studies based on a monetary model of the exchange rate that depends on a liquidity effect. ${ }^{15}$ Therefore, it is interesting to ask whether nonborrowed reserves innovations will provide stronger evidence of a monetary channel than M1. For this reason, the second monetary aggregate I use is nonborrowed reserves.

The third monetary indicator examined is the Fed funds rate. Ber-

15. For example, the model in Mussa (1982) is based on money demand equations such that shocks to money supply should imply a negative relationship with interest rates, consistent with the liquidity effect. If M1 shocks contain mostly money demand shocks, then shocks to M1 should be associated with an appreciation of the domestic currency. 
nanke and Blinder (1992) find that this rate is a stronger predictor of real economic activity than monetary variables. They argue that the Fed funds rate is relatively exogenous in the short run as a result of Federal Reserve targeting and is the appropriate monetary policy indicator. ${ }^{16}$

\section{B. Empirical Implementation}

To examine the effects of each of these three monetary variables, I estimated bivariate VARs of the logarithm of their levels together with the logarithm of the levels of the exchange rates. In order to compare the effects on exchange rates with studies of effects on interest rates, I follow the practice in the literature of estimating these VARs in levels to allow for possible cointegration among the variables and treat the monetary indicator as the first component in the vector. I also follow a procedure similar to the lag-length tests above to determine the lag length. Given a maximum lag length of 10 biweekly periods, I calculate the Wald test of zero coefficients for all lags greater than or equal to successively shorter lags until the hypothesis is rejected at the $95 \%$ confidence level. As before, the variance-covariance matrix allows for conditional heteroscedasticity, an important consideration in these systems since exchange rates are well-known to be heteroscedastic. The lag lengths and their marginal significance levels are reported in Appendix table B3.

Given these lag lengths, the VARs were estimated similarly to equation (6) above:

$$
\left[m(i)_{t}, s_{t}\right]^{\prime}=B(L)\left[m(i)_{t}, s_{t}\right]^{\prime}+e_{t}
$$

and

$$
E\left(e_{t} e_{t}^{\prime}\right)=\Sigma,
$$

where now $m(i)$ is the logarithm of the monetary indicator; $i=\mathrm{M} 1$, $\mathrm{NBR}, \mathrm{FF}$; and $s$ is the logarithm of the exchange rate for either the DM/dollar rate or the yen/dollar rate. ${ }^{17}$ From the estimates of these VARs, the impulse response functions were calculated.

In order to evaluate the significance of the responses in exchange rates, Monte Carlo experiments were performed to generate the empirical distribution of the impulse response functions. The Monte Carlo experiments were implemented as follows. First, the VAR in (10) above was estimated and the parameter estimates, $B(L)$, and the fitted

16. They also argue that the monetary transmission mechanism works because reductions in reserves by the Federal Reserve reduces the amount of loans made to customers and, therefore, aggregated demand falls. For more on the argument, see Bernanke and Blinder (1992).

17. The logarithm of the Fed funds rate was used to correspond to its treatment in Christiano and Eichenbaum (1992b). The essential results below are unchanged when using the level of the Fed funds rate. 
residuals, $e_{t}$, were saved. From these estimates, the covariance matrix, $\Sigma$, was formed. The Cholesky decomposition of $\Sigma$ was then calculated, and its lower triangular matrix form, $G$, was saved.

Then, these next steps were followed repeatedly. (i) Generate a twodimensional random variable, $v_{t}$, the length of the number of observations. (ii) Premultiply by $G$ to obtain $G^{\prime} v_{t}=e_{t}$. (iii) Add these values for $e_{t}$ to the right-hand side of (10), and generate the left-hand-side variables, $\left[m(i)_{t}, s_{t}\right]^{\prime}$. (iv) Estimate the vector autoregression in (10) and save the parameter estimates, $B(L)$. (v) Using $B(L)$, form the moving average representation of the vector autoregression, and generate the impulse response functions. (vi) Save the impulse responses and repeat 300 times. ${ }^{18}$ From these observations, the $95 \%$ bounds on the empirical distribution were obtained.

Figure 2 shows the estimates of the impulse response functions together with the $95 \%$ confidence intervals for the DM/dollar rate. The top panel shows the effect of a $1 \%$ shock in M1. As would be predicted by a monetary model, the value of the dollar declines immediately and stays lower. However, the confidence intervals show that the depreciation in the dollar is significant only between 4 and 16 weeks after the shock. Nevertheless, the significant effect of the shock of M1 on the exchange rate is somewhat surprising given previous research on exchange rates.

The middle panel of figure 2 shows the effects when nonborrowed reserves are used as monetary indicators. Unlike the M1 measure, the nonborrowed reserves shock has no immediate impact on the exchange rate. But quite interestingly, the depreciating effects on the exchange rate become significant after 4 weeks and remain significant even after 20 weeks.

The last column shows the effects of a shock in the Fed funds rate. Like nonborrowed reserves, there is no immediate effect on the exchange rate. The point estimates imply that the rise in Fed funds induces an appreciation in the dollar after 2 weeks. However, these estimates are never statistically different from the $95 \%$ level (although they are at the $90 \%$ level).

While these estimates would suggest that monetary measures might explain the exchange rate as standard models predict, the response functions for the yen/dollar rate in figure 3 give a different story. A shock to M1 induces very little variation in the yen/dollar rate, and the confidence intervals are quite large. The point estimates of impulse responses to nonborrowed reserves shocks and Fed funds shocks generally imply movements in the exchange rate in the direction suggested by a monetary model with liquidity effects. But the estimates are never significantly different from zero.

18. Experimentation with the distributions from 2,000 repetitions for several of the VARs indicated that the results were little changed by more repetitions. 

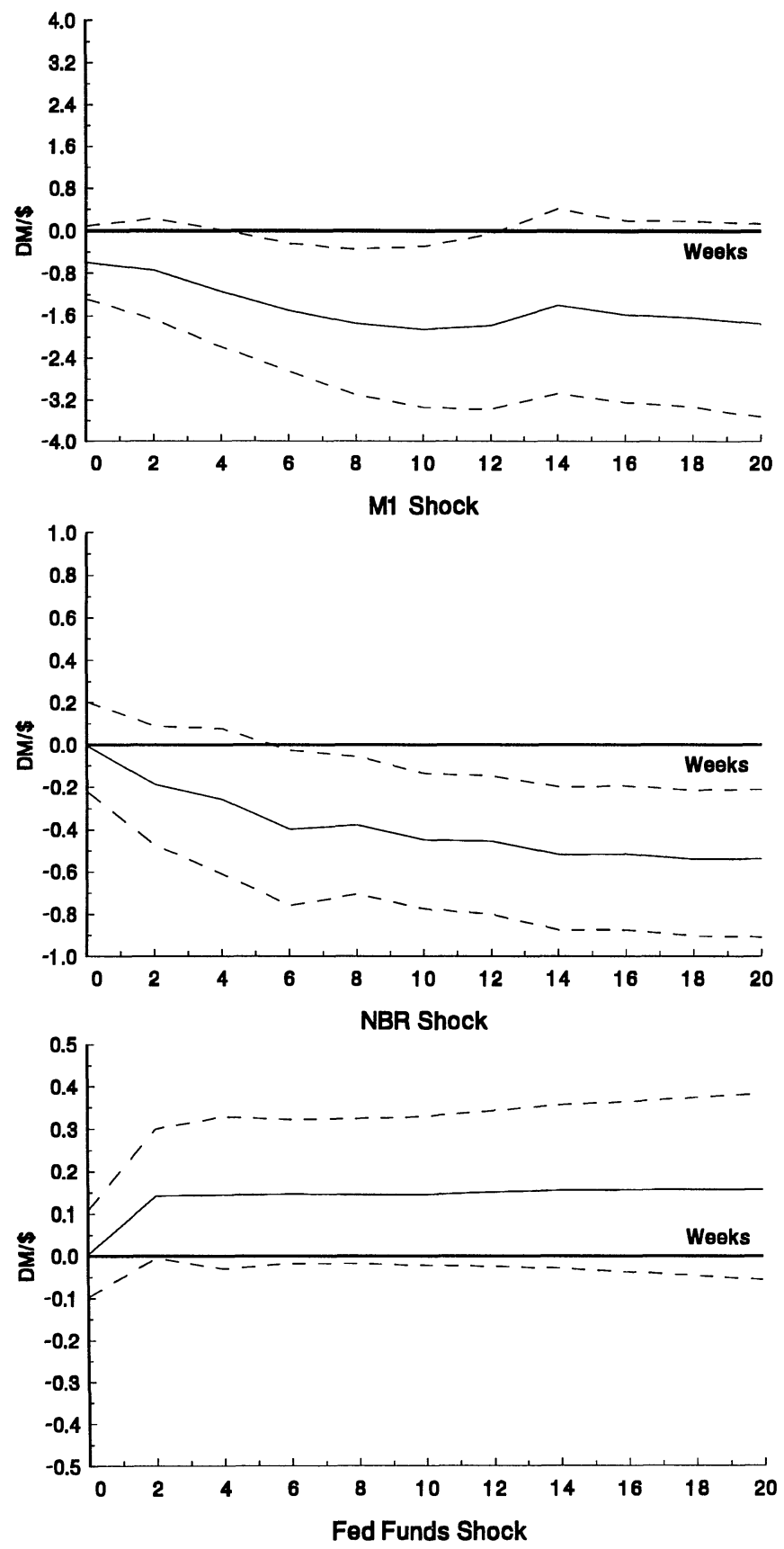

FIG. 2.-Impulse response functions of DM/dollar exchange rate from U.S. monetary shocks. The dashed line represents the $95 \%$ confidence interval from the Monte Carlo distribution. The solid line represents impulse response estimates. 

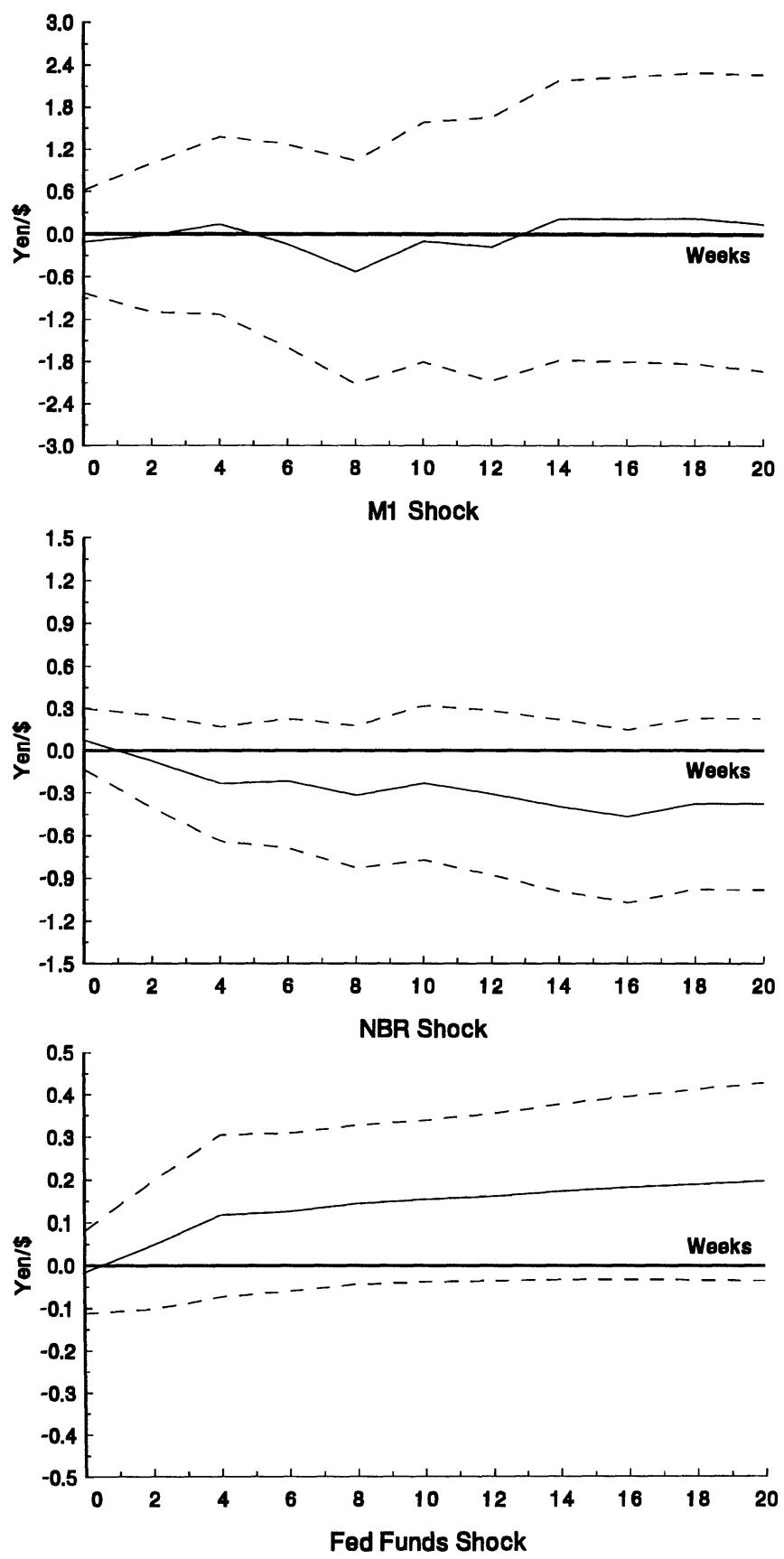

FIG. 3.-Impulse response functions of yen/dollar exchange rate from U.S. monetary shocks. The dashed line represents the $95 \%$ confidence interval from the Monte Carlo distribution. The solid line represents impulse response estimates. 


\section{Does the Exchange Rate Depend on Relative Monetary Policies?}

The focus of the previous analysis on U.S. monetary policy variables alone is an important shortcoming. As discussed above, monetary models would imply that exchange rates depend on relative money supplies. While the lack of high frequency money supply data preclude an investigation of money supply differentials over the short sample period, interest rate data can provide some information about the stance of foreign monetary policy.

Therefore, I estimated trivariate vector autoregressions similar to those examined in figures 2 and 3, but including the German and Japanese call money rates. In particular, the system estimated was

$$
\left[m(i)_{t}, r_{t}^{*}, s_{t}\right]^{\prime}=B(L)\left[m(i)_{t}, r_{t}^{*}, s_{t}\right]^{\prime}+e_{t},
$$

where $r^{*}$ is the logarithm of the German call money rate when the exchange rate is the DM/dollar rate and the Japanese call money rate when the exchange rate is the yen/dollar rate. Thus, the exchange rate was placed as last in the VAR order. These VARs were estimated, the impulse response functions calculated, and the Monte Carlo distributions generated as above.

Figure 4 depicts the impulse response functions of the DM/dollar rate from shocks to U.S. monetary aggregates controlling for the German interest rates. Strikingly, the basic pattern found in figure 2 continues to emerge. A shock in M1 is related to an immediate depreciation in the dollar. This decline is now statistically significant and continues for about 12 weeks. The nonborrowed reserves shock continues to imply a depreciation in the dollar even at 20 weeks. And finally, the Fed funds shock now becomes statistically significant after 6 weeks.

Figure 5 depicts these same impulse response functions for the yen/ dollar rate. As before, none of the impulse responses are significantly different from zero at the $95 \%$ level, although at the $90 \%$ level nonborrowed reserves are significant for some periods.

Overall, the evidence suggests that changes in monetary policy affect the exchange rate in the direction implied by standard monetary models. Except for M1, however, there is little evidence of a contemporaneous effect.

\section{Concluding Remarks}

This article has provided two new sets of empirical findings. First, it examined the relationship between foreign exchange intervention and U.S. monetary policy variables during the period from 1985 to 1990 . The evidence suggests that there were significant correlations in both directions between the two variables. Second, the article analyzed 

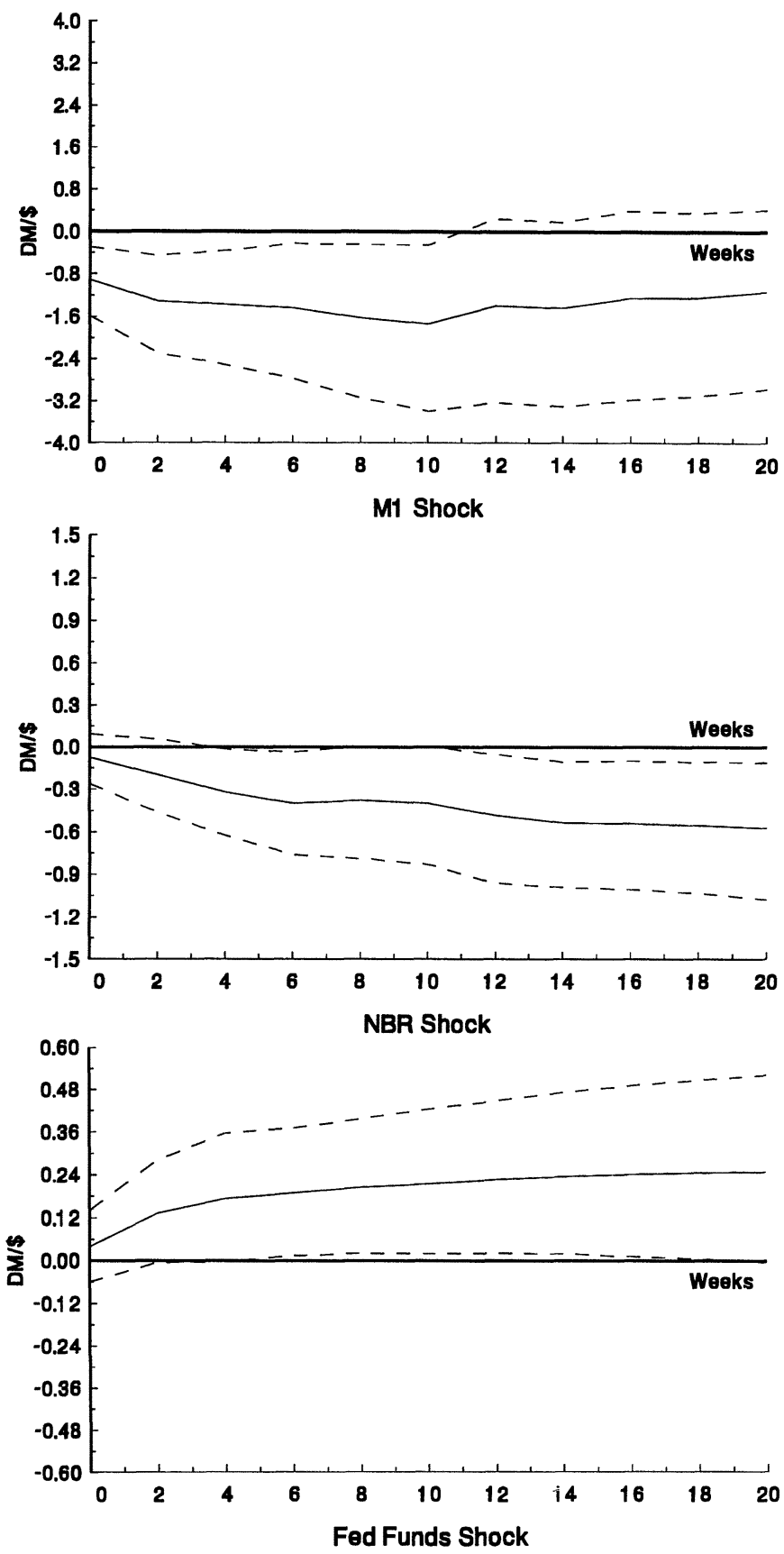

FIG. 4.-Impulse response functions of DM/dollar exchange rate from U.S. monetary shocks controlling for German interest rates. The dashed line represents the $95 \%$ confidence interval from the Monte Carlo distribution. The solid line represents impulse response estimates. 

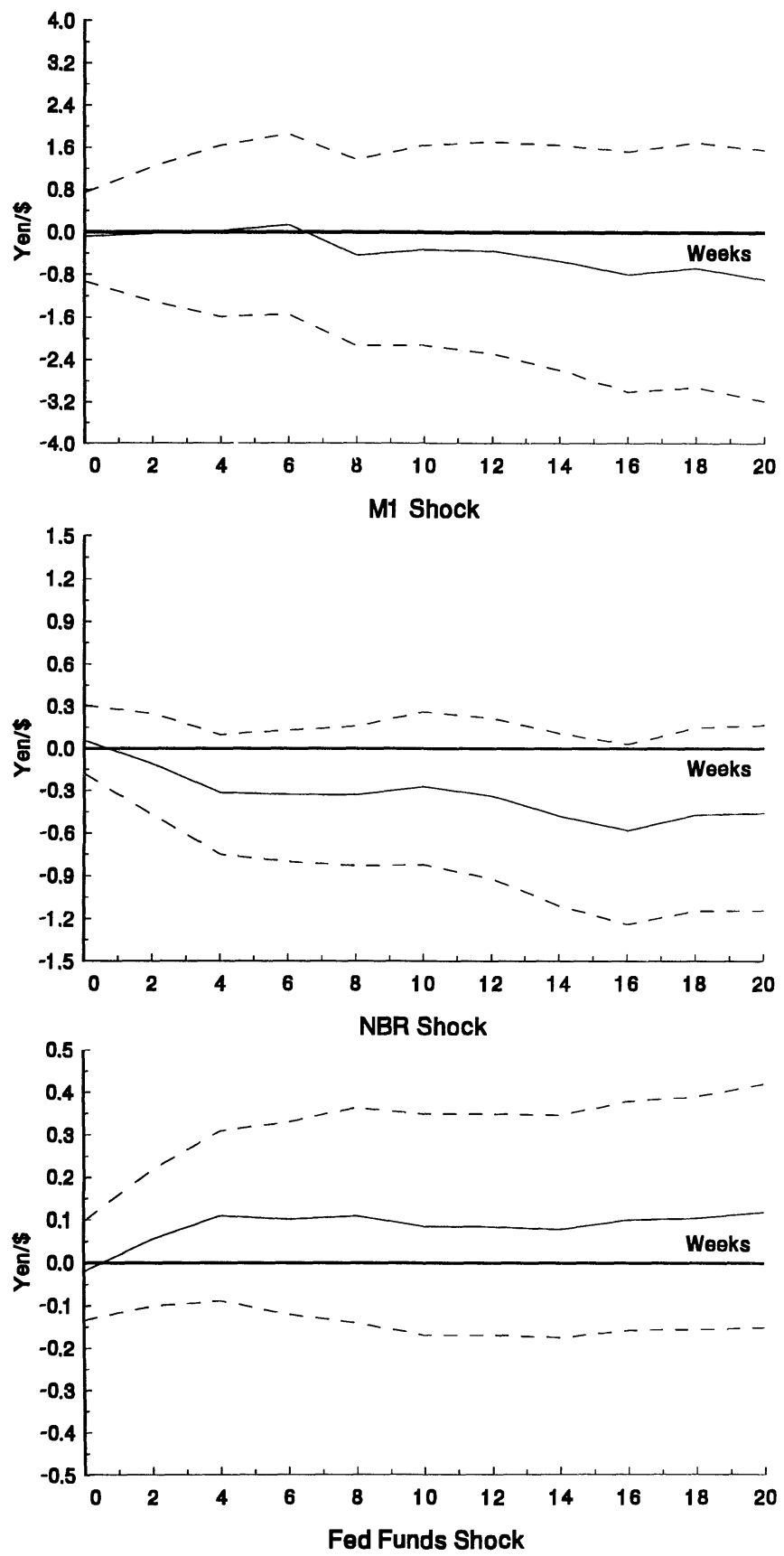

FIG. 5.-Impulse response functions of yen/dollar exchange rate from U.S. monetary shocks controlling for Japanese interest rates. The dashed line represents the $95 \%$ confidence interval from the Monte Carlo distribution. The solid line represents impulse response estimates. 
the effects on exchange rates of innovations to different measures of monetary policy variables suggested by the recent debate on the domestic monetary transmission mechanism. Interestingly, positive innovations in nonborrowed reserves appear to be more systematically related to depreciation in the dollar exchange rates than M1. This finding is consistent with the Christiano-Eichenbaum view that M1 contains a larger endogenous component relative to nonborrowed reserves.

Generally, this article has produced new empirical findings in the relationship between monetary variables, foreign exchange intervention, and exchange rates. A continuing challenge for international researchers is to provide theoretical explanations for these relationships. In addition, the evidence here leaves open several particular issues and questions.

First, the innovations in monetary policy variables did not control for real economic activity. The money supply decision presumably depends on variables such as the inflation rate and income growth. The short sample period of intervention precluded an analysis based on real variables measured monthly or quarterly. However, an issue for future research will be to reexamine the effect on the exchange rate using different measures of monetary policy controlling for real economic policy objectives.

Second, the analysis in this paper focused on the behavior of U.S. monetary variables, while the exchange rate should depend on relative monetary variables. Once foreign monetary variables are introduced, the current debate concerning the monetary transmission mechanism is doubled. The parallel question of what variables to use as foreign monetary policy indicators arises, as does how these variables feed into real economic behavior. These questions also raise the issue of whether individual-country monetary transmission processes can generate international feedback effects.

Third, this article has only documented the empirical relationship between intervention and the money supply; the reason for this correlation is not yet apparent. Although I have suggested that lags in the sterilization process implicit in borrowed reserves targeting may be responsible, future research should analyze more specifically the source of this correlation.

\section{Appendix A}

\section{Data Appendix}

Main Sources of the Data and Their Abbreviations

Federal Reserve Bulletin (FRB)

Bank for International Settlements (BIS) 
Federal Reserve Statistical Release (FRSR). Washington, D.C.: Board of Governors of the Federal Reserve System, weekly.

\section{Individual Series}

M1: Money Stock Measures and Liquid Assets, FRSR H.6 (FRB table 1.21), average of daily figures of week ending Monday.

Monetary base: Aggregate Reserves of Depository Institutions and the Monetary Base, FRSR H.3.

Nonborrowed reserves: Aggregate Reserves of Depository Institutions and the Monetary Base, FRSR H.3.

Federal funds rate: $F R B$

German call money rate: BIS

Japanese call money rate: BIS

German mark/dollar exchange rate: Foreign Exchange Rates, FRSR G.5.

Japanese yen/dollar exchange rate: Foreign Exchange Rates, FRSR G.5.

\section{Appendix B}

TABLE B1 Lag Length Tests for VARs of U.S. Monetary Variables and Intervention

\begin{tabular}{|c|c|c|c|c|}
\hline Frequency & $\Delta \mathrm{M} 1$ & $\Delta \mathrm{MB}$ & $\Delta \mathrm{NBR}$ & $\Delta \mathrm{FF}$ \\
\hline Daily & $\ldots$ & $\cdots$ & $\cdots$ & $\begin{array}{l}9 \\
(.022)\end{array}$ \\
\hline Weekly & $\begin{array}{c}1 \\
(<.001)\end{array}$ & $\cdots$ & $\cdots$ & $\begin{array}{l}2 \\
(.006)\end{array}$ \\
\hline Biweekly & $\begin{array}{c}1 \\
(<.001)\end{array}$ & $\begin{array}{c}2 \\
(.017)\end{array}$ & $\begin{array}{c}1 \\
(<.001)\end{array}$ & $\begin{array}{c}1 \\
(<.001)\end{array}$ \\
\hline
\end{tabular}

NoTE.-The table reports the first lag at which the hypothesis that all coefficients on lags greater than or equal to this number is equal to zero in at least one equation. The marginal significance levels are in parentheses and are corrected for conditional heteroscedasticity with Newey and West (1987). The maximum lag for the daily data is 10 , while for the weekly and biweekly data it is three. These systems correspond to the systems in tables 1 and 3 . VAR = vector autoregression, $\mathrm{MB}=$ monetary base, $\mathrm{NBR}=$ nonborrowed reserves, $\mathrm{FF}=\mathrm{Fed}$ funds rate.

TABLE B2 Lag Length Tests for VARs of Interest Differentials and Intervention

\begin{tabular}{lcc}
\hline Frequency & FF $-R^{\mathrm{Jpn}}$ & $\mathrm{FF}-R^{\mathrm{Ger}}$ \\
\hline Daily & 9 & 9 \\
& $(<.001)$ & $(.004)$ \\
Weekly & 2 & 3 \\
& $(.031)$ & $(.007)$ \\
\hline
\end{tabular}

NotE. - The table reports the first lag at which the hypothesis that all coefficients on lags greater than or equal to this number is equal to zero in at least one equation. The marginal significance levels are in parentheses and are corrected for conditional heteroscedasticity with Newey and West (1987). The maximum lag for the daily data is 10 , while for the weekly and biweeky data it is three. These systems correspond to the systems in tables 2 and 4 . VAR = vector autoregression, $F F=$ Fed funds rate. $R^{\mathrm{Jpn}}$ is the Japanese call money rate, and $R^{\mathrm{Ger}}$ is the German call money rate. 
TABLE B3 Lag-Length Tests for VAR Systems

A. Bivariate $\left(\log X_{t}, \log Y_{t}\right)$

\begin{tabular}{lcccc}
\hline & \multicolumn{5}{c}{$X_{t}$} \\
\cline { 2 - 5 }$Y_{t}$ & $\mathrm{M} 1$ & $\mathrm{NBR}$ & $\mathrm{MB}$ & $\mathrm{FF}$ \\
\hline $\mathrm{DM}$ & 9 & 5 & 2 & 4 \\
& $(.0405)$ & $(.0395)$ & $(5.34 \mathrm{E}-09)$ & $(.0008)$ \\
Yen & 9 & 10 & 2 & 4 \\
& $(.0032)$ & $(.0393)$ & $(2.60 \mathrm{E}-06)$ & $(.0002)$ \\
\hline
\end{tabular}

B. Trivariate $\left(\log X_{t}, \log R_{t}^{*}, \log Y_{t}\right)$

\begin{tabular}{lcccc}
\hline & \multicolumn{5}{c}{$X_{t}$} \\
\cline { 2 - 5 }$Y_{t}, R_{t}^{*}$ & $\mathrm{M} 1$ & $\mathrm{NBR}$ & $\mathrm{MB}$ & $\mathrm{FF}$ \\
\hline $\mathrm{DM}, R_{t}^{\mathrm{Ger}}$ & 8 & 8 & 8 & 4 \\
Yen, $R_{t}^{\mathrm{jpn}}$ & $(.0315)$ & $(.0389)$ & $(.0338)$ & $(.0361)$ \\
& 10 & 10 & 10 & 7 \\
& $(.0365)$ & $(.0472)$ & $(.0118)$ & $(.0133)$ \\
\hline
\end{tabular}

Note. - The table reports the first lag at which the hypothesis that all coefficients on lags greater than or equal to this number are equal to zero in at least one equation. The marginal significance levels are in parentheses. These systems correspond to the impulse response functions in figs. 2-5. $\mathrm{VAR}=$ vector autoregression, $\mathrm{MB}=$ monetary base, $\mathrm{NBR}=$ nonborrowed reserves, $\mathrm{FF}=\mathrm{Fed}$ funds rate. $R^{\mathrm{Jpn}}$ is the Japanese call money rate, and $R^{\mathrm{Ger}}$ is the German call money rate.

\section{References}

Bernanke, B., and Blinder, A. 1992. The Federal funds rate and the channels of monetary transmission. American Economic Review 82, no. 4:901-21.

Christiano, L. J., and Eichenbaum, M. 1991. Identification and the liquidity effect of a monetary policy shock. Working Paper no. 3920. Cambridge, Mass.: National Bureau of Economic Research, December.

Christiano, L. J., and Eichenbaum, M. 1992a. Liquidity effects and the monetary transmission mechanism. American Economic Review Papers and Proceedings 82, no. 2:346-53.

Christiano, L. J., and Eichenbaum, M. 1992b. Liquidity effects, monetary policy, and the business cycle. Working Paper no. 92-15. Chicago: Federal Reserve Bank of Chicago.

Dominguez, K. 1987. Does sterilized intervention influence exchange rates? A test of the signaling hypothesis. Working paper. Cambridge, Mass.: Harvard University

Dominguez, K., and Frankel, J. 1993. Does foreign exchange intervention matter? The portfolio effect. American Economic Review 83, no. 5:1356-69.

Edison, H. 1992. The effectiveness of central bank intervention: A survey of the post1982 literature. Working paper. Washington, D.C.: Federal Reserve Board of Governors.

Federal Reserve Board. 1989. Board of Governors of the Federal Reserve System Annual Report. Washington, D.C.: U.S. Government Printing Office.

Federal Reserve Board. 1991. Briefing Book for Governor Designate. Washington, D.C.: U.S. Government Printing Office.

Frenkel, J., and Mussa, M. L. 1980. The efficiency of foreign exchange markets and measures of turbulence. American Economic Review 70, no. 2:374-81.

Kaminsky, G. L., and Lewis, K. K. 1993. Does foreign exchange intervention signal future monetary policy? Working Paper no. 4298. Cambridge, Mass.: National Bureau of Economic Research. 
Klein, M., and Rosengren, E. 1991. What do we learn from foreign exchange intervention? Working paper. Worcester, Mass.: Clark University.

Klein, M., and Rosengren, E. 1992. Foreign exchange intervention as a signal of monetary policy. Working paper. Worcester, Mass.: Clark University.

Lewis, K. K. 1988. Testing the portfolio balance model: A multi-lateral approach. Journal of International Economics 24, nos. 1-2:109-27.

Lewis, K. K. 1989. Can learning affect exchange rate behavior? The case of the dollar in the early 1980s. Journal of Monetary Economics 23, no. 1:79-100.

Mark, N. 1993. Exchange rates and fundamentals: Evidence on long-horizon predictability. Working paper. Columbus: Ohio State University.

Meese, R., and Rogoff, K. 1983. Empirical exchange rate models of the 1970s: Do they fit out of sample? Journal of International Economics 14, nos. 1-2:3-24.

Mishkin, F. S. 1981. Monetary policy and long term interest rates: An efficient markets approach. Journal of Monetary Economics 7, no. 1:29-55.

Mishkin, F. S. 1982. Monetary policy and short term interest rates: An efficieni markets rational expectations approach. Journal of Finance 37, no. 1:63-72.

Mussa, M. L. 1981. The role of official intervention. Group of Thirty Occasional Papers, no. 6. New York: Group of Thirty.

Mussa, M. L. 1982. A model of exchange rate dynamics. Journal of Political Economy 90, no. 1:75-104.

Newey, W. K., and West, K. D. 1987. A simple, positive semi-definite, heteroskedasticity and autocorrelation consistent covariance matrix. Econometrica 55, no. 3:703-8.

Rogoff, K. 1984. On the effects of sterilized intervention: An analysis of weekly data. Journal of Monetary Economics 14, no. 2:133-50. 